\title{
Pengaruh Penggunaan Mulsa terhadap Pertumbuhan dan Hasil Tanaman Sawi (Brassica juncea L.) pada Jarak Tanam yang Berbeda
}

Baso Amir a

${ }^{a}$ Fakultas Pertanian, Universitas Cokroaminoto Palopo, Palopo, Sulawesi Selatan, Indonesia, email: bas_amt@yahoo.com

\section{Article Info}

\section{Article history:}

Received 1 Oktober 2018

Received in revised form 10 Oktober 2018

Accepted 15 Oktober 2018

DOI

https://doi.org/10.32938/sc.v3i04.456

Keywords:

Mulsa

Jarak Tanam

Sawi

\section{Abstrak}

Menurunnya produktivitas tanaman dapat disebabkan oleh faktor lingkungan. Kurangnya ketersediaan air, hara, perolehan cahaya serta kompetisi yang terjadi antar tanaman pada jarak tanam yang lebih rapat maupun kompetisi tanaman dengan gulma dapat mengakibatkan pertumbuhan tanaman yang tidak maksimal sehingga berdampak pada hasil produksi yang kurang. Penelitian ini bertujuan untuk mengetahui pengaruh penggunaan mulsa dengan beberapa jarak tanam yang berbeda terhadap pertumbuhan dan hasil tanaman sawi. Penelitian dilaksanakan dengan menggunakan Rancangan Acak Kelompok Lengkap (RAKL) Faktorial yang diulang sebanyak 4 (empat) kali. Faktor pertama adalah jenis mulsa terdiri dari tiga taraf yaitu M0: tanpa mulsa, M1: mulsa plastik hitam perak, M2: mulsa jerami. Faktor kedua adalah jarak tanam yang terdiri dari tiga taraf yaitu JT1: $20 \times 25 \mathrm{~cm}, \mathrm{JT} 2: 30 \times 25 \mathrm{~cm}, \mathrm{JT} 3: 40 \times 25 \mathrm{~cm}$. parameter pengamatan terdiri dari tinggi tanaman, jumlah daun, luas daun, panjang akar dan bobot segar tanaman. Analisis data dilakukan dengan menggunakan software SAS dengan analisis varian (Anova) pada taraf 5\%. Apabila hasil analisis varian menunjukkan adanya beda nyata antar perlakuan, analisis dilanjutkan dengan uji jarak ganda Duncan (DMRT). Hasil penelitian menunjukkan bahwa Pemberian mulsa jerami dengan jarak tanam 30x25 cm antar tanaman menunjukkan pengaruh yang lebih baik dengan nilai yang lebih tinggi yaitu jumlah daun 13,50 helai, luas daun $63,13 \mathrm{~cm}^{2}$, panjang akar $8,18 \mathrm{~cm}$ dan bobot segar tanaman sebanyak 210,00 gram/tanaman dibandingkan dengan perlakuan lainnya.

\section{Pendahuluan}

Tanaman sawi merupakan salah satu komoditi hortikultura yang merupakan komoditas dengan prospektif yang sangat baik untuk dikembangkan. Sawi adalah sekelompok tumbuhan dari marga Brassica yang dimanfaatkan daun atau bunganya sebagai bahan pangan (sayuran), baik segar maupun diolah Sawi mencakup beberapa spesies Brassica yang kadang-kadang mirip satu sama lain. Di Indonesia, penyebutan sawi biasanya mengacu pada sawi hijau (Brassica rapa) kelompok parachinensis, yang disebut juga sawi bakso, caisim atau caisin). Selain itu, terdapat pula sawi putih (Brassica rapa) kelompok pekinensis, disebut juga petsai yang biasa dibuat sup atau diolah menjadi asinan. Jenis lain yang kadang-kadang disebut sebagai sawi hijau adalah sesawi sayur (untuk membedakannya dengan caisim).

Produksi sawi di Indonesia fluktuatif dari tahun 2011-2015 dan cenderung mengalami penurunan dari tahun 2012-2015. Jumlah produksi dari tahun 2011 2015 yaitu 580,696 ton, 594,911 ton, 635,728 ton, 602,468 ton, dan 600,188 ton (BPS \& Dirjen Hortikultura, 2015). Hal ini menunjukkan bahwa produksi sawi cenderung tidak stabil. Di Sulawesi Selatan, jumlah produksi pada tahun 2013 sebesar 18,308 ton (BPS, Hortikultura Sul-sel, 2015). Angka ini tidak cukup besar bila dibandingkan dengan kondisi lahan yang cukup berpotensi secara geografis, klimatologis untuk syarat tumbuh tanaman sawi. Kemampuan adaptasi atau kesesuaian tanaman terhadap kondisi lingkungan seperti air, udara, suhu, hara, sinar matahari serta kompetisi hara tanaman dengan gulma menjadi faktor penentu keberhasilan produksi. Penurunan produksi dapat terjadi apabila lingkungan tumbuh tidak sesuai dengan syarat tumbuh tanaman.

Penurunan produksi yang dapat disebabkan karena terjadi kompetisi hara antara tanaman budidaya dan gulma, hal ini dapat diatasi dengan menggunakan mulsa, dapat dengan mulsa organik maupun mulsa anorganik. Penambahan mulsa dapat menekan pertumbuhan gulma serta menjaga kondisi kelembaban suhu tanah. Hasil penelitian Ramli, (2010) menunjukkan bahwa bobot segar crop yang berat pada tanaman kubis terdapat pada perlakuan tanpa mulsa dan mulsa jerami sebesar 1.002,67 g dan $885 \mathrm{~g}$. Mulsa dapat mengurangi fluktuasi suhu, memperbaiki sifat fisik dan sifat kimia tanah. Hal ini memungkinkan perkembangan tanaman lebih baik dan hasil pertanaman meningkat, baik mutu maupun kuantitasnya. Menurut Hamdani, (2009) mengemukakan penggunaan mulsa jerami padi dapat mengendalikan evaporasi sehingga tanaman tidak mengalami cekaman air. Hayati, (2010) dalam penelitiannya mengemukakan jenis mulsa organik pengaruhnya sangat nyata terhadap pertumbuhan tinggi tanaman jagung manis umur 9 HST dan komponen produksi tanaman. Hasi tertinggi diperoleh pada perlakuan mulsa jerami padi.

Jarak tanam dapat mempengaruhi pertumbuhan tanaman yang juga berkorelasi pada hasil produksi. Penerapan model atau pola jarak tanam anta tanaman berpengaruh terhadap kualitas dan kuantitas tanaman. semakin rapa jarak tanam antar tanaman, maka persaingan unsur hara, air dan sinar matahar juga semakin tinggi. Putrasamedja, (1996) menyatakan bahwa pada perlakuan jarak tanam 35 x $45 \mathrm{~cm}$ tanaman memberikan produksi benih paling tinggi yaitu 309,64 gram, kemudian disusul oleh perlakuan jarak tanam $30 \times 30 \mathrm{~cm}$ dalam produksi biji yaitu 298,63 gram pada tanaman caisim. Peningkatan produktivitas tanaman bergantung pada kesesuaian jarak tanam dan faktor lingkungan yang mendukung.

Pemanfaatan mulsa yang dikombinasikan dengan beberapa jarak tanam diharapkan dapat diketahui pengaruh yang terbaik terhadap peningkatan pertumbuhan dan hasil tanaman sawi.

\section{Metode}

Penelitian dilaksanakan di Kecamatan Belopa Kabupaten Luwu Sulawesi Selatan, dimulai pada bulan Agustus sampai September 2018. Bahan yang digunakan yaitu benih sawi, pupuk NPK, jerami padi dan mulsa plastik hitam perak. Alat yang digunakan berupa alat antara lain ember, karung, cangkul, ala tulis, meteran, timbangan analitik. Penelitian dilaksanakan dengan menggunakan
Rancangan Acak Kelompok Lengkap (RAKL) Faktorial yang diulang sebanyak 4 (empat) kali. Faktor pertama adalah jenis mulsa yang terdiri dari tiga taraf yaitu M0: tanpa mulsa, M1: mulsa plastik hitam perak, M2: mulsa jerami. Faktor kedua adalah jarak tanam yang terdiri dari tiga taraf yaitu JT1: 20x25 cm, JT2: 30x25 $\mathrm{cm}$, JT3: 40x25 cm

Parameter yang diamati terdiri dari tinggi tanaman $(\mathrm{cm})$, jumlah daun (helai), luas daun $\left(\mathrm{cm}^{2}\right)$, panjang akar $(\mathrm{cm})$ dan bobot segar tanaman (gram/tanaman). Pengukuran tinggi tanaman $(\mathrm{cm})$ dilakukan sebanyak 2 (dua) kali yaitu pada saat tanaman berumur 2 dan 4 MST (minggu setelah tanam) dengan cara mengukur tanaman mulai dari pangkal tanaman sampai ujung daun bagian paling atas. Jumlah daun diamati sebanyak 2 (dua) kali pengamatan yaitu pada saat tanaman berumur 2 dan 4 MST dengan cara menghitung jumlah daun yang telah terbentuk sempurna. Pengukuran luas daun dilakukan dengan menggunakan metode gravimetric yaitu menggambar daun secara langsung pada sehelai kertas kemudian diukur luasnya. Penghitungan luas daun dilakukan berdasarkan perbandingan antara berat replika daun dengan berat total kertas (Sitompul \& Guritno, 1995). Pengukuran panjang akar dilakukan dengan cara mengukur panjang akar mulai dari pangkal batang sampai ujung akar pengukuran dilakukan hanya 1 (satu) kali yaitu pada saat panen. Pengamatan bobot segar tanaman dilakukan hanya 1 (satu) kali yaitu pada saat panen, pengamatan dilakukan dengan cara menimbang daun dengan menggunakan timbangan analitik.

Persemaian benih sawi dilakukan dengan menggunakan wadah talang yang telah diisi dengan campuran tanah dan pupuk kandang dengan perbandingan $3: 1$. Setelah bibit berumur sekitar 2 minggu atau telah berdaun 4 helai kemudian bibit dipindahkan ke bedengan yang telah disiapkan. Penanaman dilakukan pada bedengan dengan ukuran ; tinggi sekitar $30 \mathrm{~cm}$ sebanyak 36 bedengan, ukuran masing-masing bedengan yaitu $2 \times 2$ meter, jarak tanam anta bedengan yaitu $30 \mathrm{~cm}$. Pemupukan dilakukan pada saat tanaman berumur 10 HST (hari setelah tanam). Pupuk yang digunakan adalah pupuk NPK dengan dosis $100 \mathrm{~kg} / \mathrm{ha}$. Aplikasi pupuk dilakukan dengan cara tugal yaitu membuat lubang dengan kedalaman sekitar $5 \mathrm{~cm}$ di sekitar tanaman. Penyiraman dilakukan secara rutin pada pagi dan sore hari. Pada awal pertumbuhan, penyulaman dilakukan dengan mengganti tanaman yang rusak/mati dengan bibit yang sehat yang telah disediakan sebagai bibit cadangan. Penyulaman dilakukan dengan tujuan agar jumlah tanaman tetap terjaga. Penyiangan dilakukan pada setiap seminggu sekali secara manual. Pemanenan dilakukan pada saat tanaman sudah berumur 35 hari setelah tanam (sekitar 4 minggu setelah penanaman)

Data hasil pengamatan dari setiap variabel yang telah dilakukan selanjutnya dianalisis dengan menggunakan software SAS. Analisis dengan menggunakan analisis varian (Anova) pada taraf 5\%. Apabila hasil analisis varian menunjukkan adanya beda nyata antar perlakuan, analisis dilanjutkan dengan uji jarak ganda Duncan (DMRT).

\section{Hasil dan Pembahasan \\ 3.1 Tinggi Tanaman $(\mathbf{c m})$}

Pengamatan tinggi tanaman menunjukkan bahwa terdapat perbedaan yang nyata pada saat tanaman berumur 4 MST yaitu antara tanaman yang tanpa menggunakan mulsa dengan yang menggunakan mulsa jerami (Tabel 1.)

Tinggi tanaman pada umur 2 MST tidak berbeda nyata di antara semua perlakuan, hal ini diduga karena tanaman masih dalam tahap awal pertumbuhan untuk beradaptasi pada lingkungan. Penambahan mulsa plastik maupun mulsa jerami dan beberapa metode jarak tanam belum dapat mempengaruhi pertumbuhan tinggi tanaman, seperti halnya pada tanaman yang tanpa menggunakan mulsa. Pengaruh pemberian mulsa dan beberapa metode jarak tanam terjadi pada saat tanaman berumur 4 MST. Nilai tertinggi di antara semua perlakuan yaitu pada tanaman dengan pemberian mulsa jerami dan jarak tanam $40 \times 25 \mathrm{~cm}$ dengan tinggi mencapai $36,80 \mathrm{~cm}$. Hal ini diduga karena tidak terjadi kompetisi unsur hara yang tinggi antar tanaman pada jarak tanaman yang cukup 
renggang sehingga aktivitas perakaran tanaman untuk menyerap ketersediaan hara, air dan cahaya masih dapat mencukupi kebutuhan tanaman. Menurut Sitompul \& Guritno (1995) mengemukakan bahwa tanaman tidak mengalami persaingan selama ketersediaan air, unsur hara dan cahaya pada kondisi tercukupi dari yang dibutuhkan tanaman.

Tabel 1. Tinggi Tanaman (cm) pada Umur 2 dan 4 MST

\begin{tabular}{|c|c|c|c|c|c|}
\hline \multicolumn{2}{|c|}{ Perlakuan } & \multicolumn{4}{|c|}{ Tinggi Tanaman } \\
\hline Mulsa & Jarak Tanam & $2 \mathrm{~N}$ & & $4 \mathrm{~N}$ & \\
\hline \multirow{3}{*}{ Tanpa Mulsa } & $20 \times 25 \mathrm{~cm}$ & 10,61 & $\mathrm{a}$ & 26,31 & $\mathrm{~b}$ \\
\hline & $30 \times 25 \mathrm{~cm}$ & 12,53 & $\mathrm{a}$ & 30,73 & $a b$ \\
\hline & $40 \times 25 \mathrm{~cm}$ & 11,09 & $\mathrm{a}$ & 28,48 & $\mathrm{~b}$ \\
\hline \multirow{3}{*}{$\begin{array}{l}\text { Mulsa Plastik } \\
\text { Hitam Perak }\end{array}$} & $20 \times 25 \mathrm{~cm}$ & 12,94 & $\mathrm{a}$ & 30,31 & $a b$ \\
\hline & $30 \times 25 \mathrm{~cm}$ & 13,36 & $\mathrm{a}$ & 30,06 & $\mathrm{ab}$ \\
\hline & $40 \times 25 \mathrm{~cm}$ & 12,33 & $\mathrm{a}$ & 33,28 & $\mathrm{ab}$ \\
\hline \multirow{3}{*}{ Mulsa Jerami } & $20 \times 25 \mathrm{~cm}$ & 11,14 & $\mathrm{a}$ & 26,10 & $\mathrm{~b}$ \\
\hline & $30 \times 25 \mathrm{~cm}$ & 15,11 & $\mathrm{a}$ & 33,31 & $a b$ \\
\hline & $40 \times 25 \mathrm{~cm}$ & 14,53 & $\mathrm{a}$ & 36,80 & $\mathrm{a}$ \\
\hline Rerata & & 12,63 & & 30,60 & \\
\hline $\mathrm{CV}$ & & 26,75 & & 16,19 & \\
\hline
\end{tabular}

Keterangan: Nilai-nilai yang diikuti oleh huruf yang sama menunjukkan tidak berbeda nyata pada Uji Jarak Berganda Duncan (DMRT) pada taraf nyata $5 \%$.

Daya adaptasi yang baik pada tanaman terhadap kondisi lingkungan dapat tergambarkan melalui peningkatan tinggi tanaman. Reaksi perubahan pertumbuhan tanaman menjadi lebih baik pada saat tanaman dapat beradaptasi dengan lingkungan tumbuhnya, terutama ketika tanaman berada pada jarak tanam yang sesuai. Selain jarak tanam, penggunaan mulsa juga dapat mempengaruhi pertumbuhan tinggi tanaman. Hal ini sesuai dengan pernyataan Sutarto, $d k k$. (2016) pada hasil penelitiannya menyatakan bahwa pengaplikasian macam mulsa berpengaruh pada pertumbuhan dan hasil tanaman sawi karena aplikasi mulsa dapat meningkatkan dan mempertahankan suhu tanah dalam suhu tanah yang dibutuhkan tanaman sawi, aplikasi mulsa juga dapat menekan pertumbuhan gulma, maka dengan pengaplikasian mulsa dapat meningkatkan tinggi tanaman.

\subsection{Jumlah Daun (helai)}

Pengamatan jumlah daun menunjukkan bahwa terdapat perbedaan yang nyata pada tanaman saat berumur 2 dan 4 MST pada penambahan mulsa jerami, plastik hitam perak dengan tanaman tanpa pemberian mulsa pada beberapa metode jarak tanam yang berbeda (Tabel 2.).

Tabel 2. Jumlah Daun (helai) pada Umur 2 dan 4 MST

\begin{tabular}{|c|c|c|c|c|c|}
\hline \multicolumn{2}{|c|}{ Perlakuan } & \multicolumn{4}{|c|}{ Jumlah Daun } \\
\hline Mulsa & Jarak Tanam & $2 \mathrm{M}$ & & & \\
\hline \multirow{3}{*}{ Tanpa Mulsa } & $20 \times 25 \mathrm{~cm}$ & 5,50 & $\mathrm{c}$ & 9,88 & $\mathrm{~b}$ \\
\hline & $30 \times 25 \mathrm{~cm}$ & 8,13 & $a b c$ & 11,63 & $a b$ \\
\hline & $40 \times 25 \mathrm{~cm}$ & 6,25 & $\mathrm{bc}$ & 10,13 & $\mathrm{~b}$ \\
\hline \multirow{3}{*}{$\begin{array}{l}\text { Mulsa Plastik } \\
\text { Hitam Perak }\end{array}$} & $20 \times 25 \mathrm{~cm}$ & 7,25 & $a b c$ & 11,25 & $a b$ \\
\hline & $30 \times 25 \mathrm{~cm}$ & 8,63 & $a b$ & 12,25 & $a b$ \\
\hline & $40 \times 25 \mathrm{~cm}$ & 8,25 & $a b c$ & 11,88 & $\mathrm{ab}$ \\
\hline \multirow{3}{*}{ Mulsa Jerami } & $20 \times 25 \mathrm{~cm}$ & 8,13 & $a b c$ & 11,25 & $a b$ \\
\hline & $30 \times 25 \mathrm{~cm}$ & 9,63 & $\mathrm{a}$ & 13,50 & $\mathrm{a}$ \\
\hline & $40 \times 25 \mathrm{~cm}$ & 8,25 & $a b c$ & 11,75 & $a b$ \\
\hline Rerata & & 7,78 & & 11,50 & \\
\hline $\mathrm{CV}$ & & 22,93 & & 15,61 & \\
\hline
\end{tabular}

Keterangan: Nilai-nilai yang diikuti oleh huruf yang sama menunjukkan tidak berbeda nyata pada Uji Jarak Berganda Duncan (DMRT) pada taraf nyata $5 \%$.

Berdasarkan Tabel 2. di atas dapat diketahui bahwa terjadi dinamika pertumbuhan jumlah daun yang berbeda-beda pada umur 2 dan 4 MST baik di antara beberapa jarak tanam maupun pemberian mulsa. Perlakuan mulsa jerami dengan jarak tanam 30x $25 \mathrm{~cm}$ memberikan hasil jumlah daun yang paling tinggi yaitu 9,63 pada umur 2 MST dan 13,50 pada umur 4 MST dibandingkan dengan perlakuan lainnya. Sedangkan hasil jumlah daun yang cenderung lebih rendah dibandingkan dengan perlakuan lainnya yaitu pada tanaman tanpa pemberian mulsa dengan jarak tanam 20x25 cm dengan nilai 5,50 pada umur 2 MST dan 9,88 pada umur 4 MST. Hasil daun yang optimum ini menunjukkan bahwa dengan kombinasi jerami dan jarak tanam 30x25 cm pada tanaman sawi merupakan kombinasi yang paling baik di antara perlakuan lainnya.

Apabila dilihat berdasarkan jarak tanam, kondisi jarak tanam yang lebih rapat maupun yang terlalu renggang cenderung berpengaruh terhadap kurangnya jumlah daun yang terbentuk, baik pada tanaman tanpa pemberian mulsa, pemberian mulsa jerami maupun mulsa plastik hitam perak. Hal ini diduga erat kaitannya dimana jarak tanam mempengaruhi jumlah populasi tanaman, dengan jumlah populasi tanaman yang berbeda-beda pada setiap satuan luas lahan dapat mempengaruhi laju pertumbuhan tanaman. Mawazin, (2008) menyatakan bahwa jarak tanam akan mempengaruhi efektivitas penyerapan unsur hara oleh tanaman. Semakin rapat jarak tanam semakin banyak populasi per satuan luas, sehingga persaingan hara antar tanaman semakin ketat, akibatnya pertumbuhan tanaman akan terganggu. Jarak tanam yang optimum pada setiap kondisi lahan yang berbeda dapat mempengaruhi penerimaan cahaya pada daun untuk kebutuhan fotosintesis.

\subsection{Luas Daun $\left(\mathrm{cm}^{2}\right)$, Panjang Akar (cm) dan Bobot Segar Tanaman} (gram/tanaman)

Hasil pengamatan menunjukkan terdapat perbedaan yang nyata pada luas daun, panjang akar dan bobot segar tanaman antara pemberian mulsa jerami pada jarak 30x25 cm dan 40x25 cm dengan tanaman tanpa pemberian mulsa pada jarak $20 \times 25 \mathrm{~cm}$ (Tabel 3.)

Tabel 3. Luas Daun $\left(\mathrm{cm}^{2}\right)$, Panjang Akar $(\mathrm{cm})$ dan Bobot Segar Tanaman (gram/tanaman)

\begin{tabular}{|c|c|c|c|c|}
\hline \multicolumn{2}{|c|}{ Perlakuan } & \multirow{2}{*}{ Luas Daun $\left(\mathrm{m}^{2}\right)$} & \multirow{2}{*}{$\begin{array}{c}\text { Panjang } \\
\text { Akar }(\mathrm{cm})\end{array}$} & \multirow{2}{*}{$\begin{array}{c}\text { Bobot Segar } \\
\text { Tanaman } \\
\text { (gram/tanaman) }\end{array}$} \\
\hline Mulsa & Jarak Tanam & & & \\
\hline \multirow{3}{*}{ Tanpa Mulsa } & $20 \times 25 \mathrm{~cm}$ & $39,38 \mathrm{~b}$ & $4.69 \mathrm{c}$ & $92.50 \mathrm{c}$ \\
\hline & $30 \times 25 \mathrm{~cm}$ & $51,50 \mathrm{ab}$ & $6.16 \mathrm{abc}$ & $131.25 \mathrm{abc}$ \\
\hline & $40 \times 25 \mathrm{~cm}$ & $50,00 \mathrm{ab}$ & $5,06 \mathrm{bc}$ & $102,50 \mathrm{bc}$ \\
\hline \multirow{3}{*}{$\begin{array}{l}\text { Mulsa Plastik } \\
\text { Hitam Perak }\end{array}$} & $20 \times 25 \mathrm{~cm}$ & $51,75 \mathrm{ab}$ & $6,00 \mathrm{abc}$ & $141,25 \mathrm{abc}$ \\
\hline & $30 \times 25 \mathrm{~cm}$ & $54,88 \mathrm{ab}$ & $6,64 \mathrm{abc}$ & $142,50 \mathrm{abc}$ \\
\hline & $40 \times 25 \mathrm{~cm}$ & $60,13 \mathrm{ab}$ & $6,31 \mathrm{abc}$ & $156,25 \mathrm{abc}$ \\
\hline \multirow{3}{*}{ Mulsa Jerami } & $20 \times 25 \mathrm{~cm}$ & $54,75 \mathrm{ab}$ & $6,54 \mathrm{abc}$ & $103,75 \mathrm{bc}$ \\
\hline & $30 \times 25 \mathrm{~cm}$ & $63,13 \mathrm{a}$ & 8,18 a & $210,00 \mathrm{a}$ \\
\hline & $40 \times 25 \mathrm{~cm}$ & $58,13 \mathrm{ab}$ & $7,76 \mathrm{ab}$ & $200,00 \mathrm{ab}$ \\
\hline Rerata & & 53,74 & 6,37 & 142,22 \\
\hline$\overline{\mathrm{CV}}$ & & 23,87 & 28,10 & 43,41 \\
\hline
\end{tabular}

Keterangan: Nilai-nilai yang diikuti oleh huruf yang sama menunjukkan tidak berbeda nyata pada Uji Jarak Berganda Duncan (DMRT) pada taraf nyata $5 \%$.

Luas daun dengan nilai tertinggi terdapat pada perlakuan mulsa jerami dengan jarak tanam $30 \times 25 \mathrm{~cm}$ dengan nilai $63,13 \mathrm{~m}^{2}$, begitupun dengan panjang akar dengan nilai $8,18 \mathrm{~cm}$ dan bobot segar tanaman dengan nilai 210,00 gram/tan. Sedangkan yang memberikan hasil terendah yaitu pada tanaman tanpa pemberian mulsa dengan jarak tanam 20x25 cm dengan hasil luas daun $39,39 \mathrm{~m}^{2}$, panjang akar 4,69 $\mathrm{cm}$ dan bobot segar tanaman 92,50 gram/tan.

Nilai luas daun yang tertinggi pada pemberian mulsa jerami dengan jarak tanam 30x25 cm diduga bahwa dengan jarak tanam antar tanaman dapat berkorelasi dengan perolehan sinar matahari untuk proses fotosintesis pada daun sehingga dapat memaksimalkan pembentukan dan perubahan ukuran luas daun. Menurut Fahruddin, (2009) mengemukakan bahwa luas daun yang tinggi akan menyebabkan proses fotosintesis dapat berjalan dengan baik. Dengan luas daun yang tinggi, maka cahaya akan dapat lebih mudah diterima dengan baik oleh daun untuk proses fotosintesis. Sementara, dengan pemberian mulsa jerami diduga dapat menjaga kondisi kelembaban tanah dan ketersediaan Nitrogen bagi pertumbuhan tanaman terutama pada daun. Menurut Lingga, (1991) mengemukakan bahwa kesuburan daun akan cepat berubah dan dapat menumbuhkan tunas baru karena penyerapan hara $\mathrm{N}$ sehingga dapat meningkatkan pembentukan dan pertumbuhan daun pada tanaman.

Luas daun berkorelasi dengan jumlah bobot segar tanaman. Hasil pengamatan bobot segar tanaman yang tertinggi juga terdapat pada perlakuan mulsa jerami dengan jarak tanam 30×25 cm. Hasil penelitian Kholidin \& Barus, (2015) menunjukkan bahwa penambahan mulsa jerami padi dapat meningkatkan jumlah dan luas daun serta bobot segar total pertanaman sawi. Hal ini sejalan dengan pendapat Lahadassy $d k k$. (2007), untuk mencapai bobot segar tanaman yang optimal, tanaman masih membutuhkan banyak energi maupun unsur hara agar peningkatan jumlah maupun ukuran sel dapat mencapai optimal serta memungkinkan adanya peningkatan kandungan air tanaman yang optimal pula, sebagian besar bobot segar tanaman disebabkan oleh kandungan air. Air sangat berperan terhadap turgiditas sel sehingga sel-sel daun akan membesar.

Kombinasi pemberian mulsa jerami dengan jarak tanam 30x25 cm menunjukkan nilai yang tertinggi pada panjang akar dibandingkan dengan perlakuan lainnya terutama dengan tanaman tanpa pemberian mulsa dengan jarak tanam yang lebih rapat yaitu 20x25 cm menunjukkan hasil panjang akar yang paling rendah. Hal ini menunjukkan bahwa sistem perakaran tanaman berhubungan dengan kondisi lingkungan seperti ketersediaan air dan hara. Kondisi lingkungan sangat berhubungan terhadap laju pertumbuhan tanaman. Menurut Purnama $d k k$. (2013) menyatakan bahwa dengan perakaran yang banyak hal tersebut juga dapat berpengaruh pada diameter batang tanaman pakchoy. Semakin besar diameter tanaman pakchoy, maka menandakan tanaman pakchoy memiliki banyak cadangan makanan yang nantinya akan berpengaruh pada hasil berat segar tajuk.

Kompetisi perolehan hara pada tanaman dapat terjadi bergantung pada tingkat kesuburan lahan dan jarak tanam antar tanaman, pada kondisi ini dapat mempengaruhi pertumbuhan tanaman terutama pertumbuhan akar. Selain itu, kondisi tanah tanpa pemberian mulsa memiliki tingkat evaporasi yang cukup tinggi, evaporasi yang tinggi mengakibatkan kadar air tanah berkurang sehingga dapat menghambat pertumbuhan akar. Menurut Sutarto dkk. (2016) mengemukakan bahwa aplikasi mulsa dapat meningkatkan dan mempertahankan kelembaban dan menjaga suhu tanah agar tetap stabil dalam suhu yang rendah 
dan dapat mengurangi kompetisi tanaman sawi dengan gulma. Aplikasi mulsa bermanfaat untuk melindungi agregat tanah dari kerusakan oleh air hujan, penyerapan air oleh tanah, mengurangi kecepatan aliran permukaan, mengurangi laju evaporasi dan mengendalikan pertumbuhan gulma.

\section{Simpulan}

Kombinasi pemberian mulsa dan jarak tanam memberikan hasil yang beragam terhadap pertumbuhan dan hasil tanaman sawi. Jarak tanam yang lebih rapat $20 \times 25 \mathrm{~cm}$ dan lebih renggang 40×25 cenderung memberikan pertumbuhan dan hasil yang kurang pada tinggi tanaman, jumlah daun, luas daun, panjang akar dan bobot segar tanaman baik pada tanaman dengan pemberian mulsa plastik hitam perak, mulsa jerami dan tanpa menggunakan mulsa.

Pemberian mulsa jerami dengan jarak tanam 30x25 cm antar tanaman menunjukkan pengaruh yang lebih baik dengan nilai yang lebih tinggi yaitu jumlah daun 13,50 helai, luas daun $63,13 \mathrm{~cm}^{2}$, panjang akar $8,18 \mathrm{~cm}$ dan bobot segar tanaman sebanyak 210,00 gram/tanaman dibandingkan dengan perlakuan lainnya.

\section{Pustaka}

Badan Pusat Statistik dan Direktorat Jenderal Hortikultura. 2015. Produksi Sayuran di Indonesia.

Badan Pusat Statistik Hortikultura Sulawesi Selatan. 2015. Produksi Sayuran di Sulawesi Selatan.

Fahrudin, F. 2009. Budidaya Caisim (Brassica juncea L.) Menggunakan Ekstrak Teh dan Pupuk Kascing. Skripsi. Surakarta: Fakultas Pertanian. Universitas Sebelas Maret.

Hamdani, 2009. Pengaruh Jenis Mulsa terhadap Pertumbuhan dan Hasil Tiga Kultivar Sawi (Brassica juncea L.) yang Ditanam di Dataran Medium. Bandung: Fakultas Pertanian, Universitas Padjadjaran.

Hayati, E. 2010. Pengaruh Pupuk Organik dan Anorganik terhadap Kandungan Logam Berat Dalam Tanah dan Jaringan tanaman Selada. Jurnal Floratek. 5(2): 113-123.

Lahadassy. J., A.M Mulyati dan A.H Sanaba, 2007. Pengaruh Konsentrasi Pupuk Organik Padat Daun Gamal terhadap Tanaman Sawi, Jurnal Agrisistem, 3 (6) : 51-55.

Lingga, P. 1991. Kotoran Ternak Penyubur Tanah. Jakarta: Penebar Swadaya.

Kholidin, M. Rauf, A,. dan Barus, H.N. 2015. Respon pertumbuhan dan hasil tanaman sawi (Brassica juncea L) terhadap kombinasi pupuk organik, anorganik dan mulsa di lembah palu. e_J Agrotekbis 4(1): 1-7.

Mawazin dan H. Suhaendi. 2008. Pengaruh jarak tanam terhadap pertumbuhan diameter Shorea parvifolia Dyer. J. Penelitian Hutan dan Konservasi. 5(4): 381-388.

Purnama, R. H., S. J. Santoso dan S. Hardiatmi. 2013. Pengaruh dosis pupuk kompos enceng gondok dan jarak tanam terhadap pertumbuhan dan hasil tanaman sawi (Brassica juncea L.). J. Inovasi Pertanian. 12(2): 95-107.

Putrasamedja, Sartono. 1996. Pengaruh Jarak Tanam Terhadap Produksi Benih Caisim. Prosiding Seminar Ilmiah Nasional Komoditas Sayuran. Lembang: Balitsa.

Ramli. 2010. Respon Varietas Kubis (Brassica oleraceae) Dataran Rendah Terhadap Pemberian Berbagai Jenis Mulsa. Agroland. 1(1): 30-37.

Sitompul, S. M. dan B. Guritno. 1995. Analisis Pertumbuhan Tanaman. Yogyakarta: Gadjah Mada University Press.

Sutarto, U.A., Koesriharti dan Aini, N. 2016. Respon Tiga Jenis Sawi (Brassica sp.) Terhadap Aplikasi Macam Mulsa. Jurnal Produksi Tanaman. 4(6): $447-$ 453. 